\title{
EXCLUSIVIDAD DE LA JURISDICCIÓN Y TUTELA JUDICIAL EFECTIVA: SOBRE LAS FUNCIONES EN EL PROCESO DE LOS LETRADOS DE LA ADMINISTRACIÓN DE JUSTICIA (A PROPÓSITO DE LA STC 58/2016, DE 17 DE MARZO)
}

\author{
Jesús María GonZÁLez GARCía \\ Departamento de Derecho Procesal \\ Facultad de Derecho. UCM \\ jmglez@der.ucm.es
}

\section{INTRODUCCIÓN}

La STC 58/2016 (Pleno), de 17 de marzo, ha declarado la inconstitucionalidad y nulidad del primer párrafo del apartado 2 del art. 102 bis de la Ley 29/1998, de 13 de julio, reguladora de la jurisdicción contenciosoadministrativa (en adelante, LJCA). La ratio decidendi de esta decisión es que el precepto no garantizaba que la resolución a que se refiere la norma anulada (el decreto resolutivo del recurso de reposición contra diligencias de ordenación) pudiera ser revisada en todos los casos por el juez o, en su caso, colegio de jueces, en cuanto que exclusivos titulares de la potestad jurisdiccional.

La decisión zanja una cuestión muy controvertida en los últimos años y tiene una fuerza expansiva que necesariamente la hará trascender del específico terreno de lo contencioso-administrativo hacia el resto de los órdenes jurisdiccionales, despejando con ello algunas incógnitas afectantes a los letrados de la Administración de Justicia (nuestros antañones «secretarios judiciales», así redenominados por la Ley Orgánica 7/2015, de 21 de julio, por la que se modifica la Ley Orgánica 6/1985, de 1 de julio, del Poder Judicial) y su posición en el proceso. Y no en obiter dicta, sino como fundamento del fallo. La STC 58/2016, más allá de su incidencia en el precepto cuestionado, pone sobre el tapete un asunto general en el plano de la organización de los órganos jurisdiccionales y de las no siempre fáciles relaciones de interdependencia entre los profesionales que desempeñan en ellos su función, ajustándolas a términos constitucio- 
nales: específicamente, cuáles son las fronteras que, desde la Ley 13/2009, de 3 de noviembre, de reforma de la legislación procesal para la implantación de la nueva Oficina Judicial (que a su vez es desarrollo de la reforma orgánica producida por la Ley Orgánica 19/2003, de 23 de diciembre, de modificación de la Ley Orgánica 6/1985, de 1 de julio, del Poder Judicial) existen entre las funciones del juez y las del letrado de la Administración de Justicia, dentro del complejo equilibrio de poderes y funciones resultante del diseño actual de la oficina judicial; y cómo se cohonestan unas y otras, desde el reconocimiento de la posición central de los jueces y magistrados, como exclusivos titulares de la potestad jurisdiccional, ex art. 117.3 de nuestra Carta Magna.

Como decimos, la coexistencia de facultades decisorias de los jueces y magistrados, por un lado, y de los letrados de la Administración de Justicia, por otro, ha sido fuente de problemas, no sólo de carácter conceptual (considerando la posición cimera que la Constitución otorga a los primeros y el cambio del rol tradicionalmente asignado al secretario judicial como fedatario público de los actos del proceso, tras la reforma de 2009), sino también de operatividad práctica, con incidencia en procesos concretos - lo cual es lo mismo que decir que en los propios justiciables-. Puede decirse por ello que la resuelta era una cuestión candente y, sin temor de caer en la exageración, que la STC 58/2016 es una de las decisiones más destacadas del Tribunal Constitucional en los últimos años, al menos en el plano de la Administración de Justicia, que no ha pasado desapercibida (quizás sin la atención mediática de otras resoluciones del Alto Tribunal) en sectores académicos y profesionales y, como cabría esperar, entre el colectivo principalmente afectado, del que han surgido encendidas opiniones y críticas acerbas, como no podría ser de otro modo y como suele ocurrir siempre que están en juego intereses profesionales, sea cual sea el colectivo de que se trate.

Antes, no obstante, de valorar el contenido de lo decidido, lejos del apasionamiento corporativo y de las lógicas distorsiones que éste suele producir, es pertinente exponer de forma resumida las circunstancias de hecho del caso. 


\section{ANTECEDENTES DEL CASO: EL RECUSO DE AMPARO NÚM. 4577/2011}

\section{Un caso de vulneración del derecho al proceso sin dilaciones indebidas en el señalamiento de la vista del procedimiento abreviado contencioso-administrativo}

La STC 58/2016 resuelve una cuestión interna de inconstitucionalidad elevada al Pleno del Tribunal Constitucional por su Sala Segunda. La auto-cuestión tuvo su origen en un recurso de amparo ${ }^{1}$ interpuesto por un ciudadano de nacionalidad ecuatoriana contra el que se había dictado orden de expulsión del territorio nacional (de fecha de 22 de septiembre de 2010) por la Delegación del Gobierno en Madrid, por carecer de documentación que acreditase su estancia legal en España. Previa obtención como medida cautelarísima de la suspensión de la orden administrativa de expulsión, el afectado la recurrió ante los Juzgados de lo Contencioso-Administrativo de Madrid (demanda de 10 de diciembre de 2010) por los cauces del procedimiento abreviado contencioso-administrativo (art. 78 LJCA), de tramitación muy cercana a la del juicio verbal civil (art. 437 LEC y ss.).

La demanda fue admitida a trámite por diligencia de ordenación, tal como establece el art. 78.3 LJCA tras su reforma por la Ley 13/2009, y en la propia resolución se señaló fecha para la celebración de la vista del juicio oral, en cumplimiento igualmente de sus nuevas competencias en materia procesal (art. 78.3 LJCA, párrafo segundo, en relación con el art. 182.4 LEC). El precepto no impone al órgano judicial un plazo para el señalamiento, silencio bastante significativo pero que demuestra mayor realismo que el art. 440.1 LEC, párrafo primero, en su redacción original, el cual establecía entonces (antes de la reforma del juicio verbal civil por la Ley 42/2015, de 5 de octubre) que «el secretario judicial citará a las partes para la celebración de vista en el día y hora que a tal efecto señale, debiendo mediar diez días, al menos, desde el siguiente a la citación y sin que puedan exceder de veinte».

Como consecuencia de la falta de disponibilidad de sala de vistas en el órgano judicial, la vista fue señalada para el 22 de abril de 2014, a las 10:30 horas; es decir, casi tres años después de la fecha de la diligencia de orde-

\footnotetext{
${ }^{1}$ RA 4577-2011, ponente Sra. Asua Batarrita.
} 
nación que la acordaba ( 25 de abril de 2011) y a tres años y medio de la orden administrativa de expulsión. El recurrente consideró, con razón, que no era aceptable esa demora desde el punto de vista de su derecho a un proceso sin dilaciones indebidas (art. 24.2 CE), paradójicamente en un procedimiento que la ley califica como «abreviado» y tratándose de un asunto de escasa complejidad, y por ello interpuso recurso de reposición contra la diligencia de ordenación en lo que atañía a la fecha del señalamiento; en el recurso solicitó su adelanto pero sin éxito, porque el secretario del juzgado desestimó el recurso por Decreto de 26 de mayo de 2011, que confirmó en todos su extremos la diligencia de ordenación recurrida.

Ése es el momento procesal en el que entra en juego el precepto cuestionado (el art. 102 bis, párrafo dos, apartado 1, LJCA), según el cual «[c]ontra el decreto resolutivo de la reposición no se dará recurso alguno, sin perjuicio de reproducir la cuestión al recurrir, si fuere procedente, la resolución definitiva», norma que vagamente se refleja en el espejo del art. 454 bis, párrafo 1, LEC, aun con significativas diferencias ${ }^{2}$. La previsión legal se refrendaba por el tenor del art. 79.2 LJCA, en cuya virtud «[n] o es admisible el recurso de reposición contra las resoluciones expresamente exceptuadas del mismo en esta Ley, ni contra los autos que resuelvan los recursos de reposición y los de aclaración».

Un dato relevante desde el punto de vista de la cuestión interna de inconstitucionalidad es que - como se ve-, tras la reforma operada por la Ley 13/2009, la decisión sobre el señalamiento ya no la adopta el juez, sino el letrado de la Administración de Justicia en diligencia de ordenación. El recurso procedente contra las diligencias de ordenación en el proceso contencioso-administrativo, a salvo de norma especial, es, tras la reforma mencionada y de acuerdo con el nuevo art. 102 bis LJCA, el recurso de reposición, recurso no devolutivo que resuelve el propio letrado de la Administración de Justicia. Ahora bien, eso no significa, como se ha expuesto, que la decisión del secretario no pueda ser objeto de control judicial, al menos en abstracto, puesto que, según el apartado dos de este último precepto, contra los decretos que dicte el secretario judicial resolviendo un recurso de reposición no cabe recurso alguno, sin perjuicio de

${ }^{2}$ Como luego veremos: «Art. 454 bis.1. Contra el decreto resolutivo de la reposición no se dará recurso alguno, sin perjuicio de reproducir la cuestión, necesariamente, en la primera audiencia ante el tribunal tras la toma de la decisión y, si no fuera posible por el estado de los autos, se podrá solicitar mediante escrito antes de que se dicte la resolución definitiva para que se solvente en ella». 
la posibilidad de plantear de nuevo la impugnación en el recurso que proceda contra la sentencia.

En el caso, el estado de la legislación procesal aplicable tras la Ley 13/2009 suponía que cuando la parte pretendiera obtener amparo del Tribunal Constitucional por vulneración del derecho fundamental al proceso sin dilaciones indebidas como consecuencia de los retrasos en el señalamiento en el proceso contencioso-administrativo (en las condiciones señaladas) se podría acudir directamente en amparo ante el Tribunal Constitucional sin que el personal jurisdicente (jueces o magistrados) hubiera tenido la oportunidad de reparar la lesión en el propio proceso y amparar el derecho, en su caso, en vía jurisdiccional. En otras palabras, se estaría admitiendo directamente un recurso de amparo por los cauces del art. 44 LOTC contra un acto que no emanaría de un juez o magistrado, sino de un funcionario del órgano judicial que no ostenta potestad jurisdiccional, de conformidad con el art. 117.3 CE.

\section{El problemático acceso a la tutela de amparo constitucional de las dilaciones indebidas producidas como consecuencia de la decisión que acuerda el señalamiento del juicio}

Centrado así el problema, la aplicación al caso del art. 102 bis LJCA planteaba serias dudas de compatibilidad con nuestra Constitución, pues, al excluirse la posibilidad de recurso directo ante el juez contra el decreto resolutorio del recurso de reposición, la norma sólo brindaba una opción diferida e indirecta para obtener la reparación del derecho en el seno del propio proceso, salvaguardando con ello la subsidiariedad del recurso de amparo; esa posibilidad era la de plantear la impugnación una vez concluida la primera instancia en el recurso procedente contra la sentencia que se dictase (de ser desfavorable a la parte), es decir, tras la consumación de lo ordenado en el señalamiento que se discute. En el caso, eso planteaba una auténtica aporía, pues se impide la revisión directa por parte del juez de una decisión adoptada por el letrado de la Administración de Justicia en materia de derechos fundamentales - del derecho al proceso sin dilaciones indebidas-, pero haciendo inviable dicho control por el cauce diferido previsto en la propia norma, a través del recurso procedente contra la sentencia, y ello como consecuencia de la propia configuración de este derecho fundamental.

En efecto, el derecho fundamental al proceso sin dilaciones indebidas (art. 24.2 CE) presenta ciertas singularidades de configuración y trata- 
miento procesal a través del recurso de amparo que lo diferencia del resto de los derechos fundamentales a que se refiere el art. 53.2 CE. Nuestro ordenamiento establece dos cauces principales de reacción jurídica contra dilaciones indebidas o retrasos injustificados en el proceso. En primer término, el retraso injustificado o no razonable es constitutivo de un supuesto de funcionamiento anormal de la Administración de Justicia (art. 292 LOPJ, en desarrollo del art. $121 \mathrm{CE})^{3}$, susceptible de reparación por vía indemnizatoria ante la jurisdicción contencioso-administrativa, previo reconocimiento de que el retraso es injustificado, y siempre que se haya derivado de él un daño evaluable en metálico y sea imputable a la Administración de Justicia, en sentido lato, y no al propio comportamiento del afectado. Por otro lado, el retraso injustificado vulnera el derecho fundamental al proceso sin dilaciones indebidas (art. 24.2 CE), susceptible de tutela ante el Tribunal Constitucional a través del recurso de amparo, previo agotamiento de los recursos en vía judicial, es decir, siempre que la propia jurisdicción ordinaria no haya tenido la oportunidad de tutelar el derecho en positivo, poniendo fin a la dilación denunciada y preservando con ello la subsidiariedad de la jurisdicción constitucional. Estos dos instrumentos no se solapan entre sí, sino que desempeñan diferentes papeles dentro del sistema global de reacción frente a dilaciones indebidas. La reclamación de responsabilidad patrimonial al Estado por funcionamiento anormal de la Administración de Justicia se inicia tras la terminación del proceso, esto es, una vez consumado el daño y no habiendo sido reparado en vía jurisdiccional a pesar de haber sido denunciado por la parte, al estar vedado al Estado proceder a la reparación patrimonial por funcionamiento anormal del Estado-juez cuando el proceso está aún pendiente y no ha concluido por resolución firme. Por su parte, el recurso de amparo por dilaciones indebidas requiere como condición necesaria que la lesión que se denuncia sea aún reparable, es decir, que el proceso en el que se denuncia la dilación no haya concluido en el momento de interposición de la demanda, de suerte que la sentencia estimatoria que declare la vulneración del derecho fundamental tenga el efecto positivo de ordenar al órgano judicial que se ponga fin a la dilación indebida denunciada en el propio proceso, de no haber concluido éste durante la pendencia del recurso de amparo.

3 A su vez, concreción del principio general de responsabilidad del Estado reconocido en el art. 106.2 CE. Dice así el art. 121 CE: «Los daños causados por error judicial, así como los que sean consecuencia del funcionamiento anormal de la Administración de Justicia, darán derecho a una indemnización a cargo del Estado, conforme a la Ley». 
Como se ve, existe una diferencia sustancial entre el derecho al proceso sin dilaciones indebidas y el resto de los derechos fundamentales susceptibles de amparo desde el punto de vista de su tutela constitucional: si, con carácter general, no es viable un recurso de amparo cuando todavía no ha concluido el proceso en el que se denuncia la lesión (la «vía judicial» de la que nos habla el art. 44 LOTC), hecho que es, por tanto, causa de inadmisión del recurso por considerarse el recurso de amparo prematuro ${ }^{4}$, sólo tendrá éxito el recurso de amparo por vulneración del derecho al proceso sin dilaciones indebidas precisamente cuando el proceso no ha concluido al tiempo de la interposición de la demanda ${ }^{5}$, puesto que, si el proceso ya hubiera terminado, no sería ontológicamente posible reparar la lesión producida, no quedando a favor de los afectados otra vía expedita más que la acción de responsabilidad patrimonial ex art. 292 LOPJ y concordantes ${ }^{6}$, fuera, por tanto, del sistema constitucional de tutela de derechos fun-

${ }^{4}$ SSTC 139/2014, de 8 de septiembre, FJ 3. ${ }^{\circ}$; 99/2009, de 27 de abril; FJ 2. ${ }^{\circ}$, o 85/2006, de 27 de marzo, FJ $2 .^{\circ}$ Dice esta última: «Cuando, por su propia decisión el ciudadano ha intentado un remedio procesal o recurso contra una resolución judicial, el proceso constitucional no puede iniciarse hasta que la vía judicial, continuada a través de ese remedio o recurso, no se haya extinguido, dado que contradice el carácter subsidiario del recurso de amparo su coexistencia temporal con otro recurso seguido en la vía judicial ordinaria». También SSTC 189/2002, de 14 de octubre, FJ 6. ${ }^{\circ}$; 15/2003, de 28 de enero, FJ 3.. ; 82/2004, de 10 de mayo, FJ 3. ${ }^{\circ}$; 97/2004, de 24 de mayo, FJ 3. ${ }^{\circ}$, y 13/2005, de 31 de enero, FJ 3.o, entre otras muchas.

${ }^{5}$ La vulneración del derecho a un proceso sin dilaciones indebidas no es invocable en amparo una vez concluido el proceso judicial $a$ quo en el que se afirman producidas tales dilaciones (SSTC 49/2006 de 13 de febrero, FJ 5. ${ }^{\circ}$; 237/2001, de 18 de diciembre, FJ 3. ${ }^{\circ}$, y 146/2000, FJ 3. ${ }^{\circ}$ ). Sólo en aquellos supuestos en los que, tras la denuncia del interesado (carga procesal que le viene impuesta como un deber de colaboración de la parte con el órgano judicial en el desarrollo del proceso), el órgano judicial no haya adoptado las medidas pertinentes para poner fin a la dilación en un plazo prudencial o razonable, podrá entenderse que la vulneración constitucional no ha sido reparada en la vía judicial ordinaria, y puede entonces ser examinada por el Tribunal Constitucional (por todas, SSTC 177/2004, de 18 de octubre, FJ 2. ${ }^{\circ} ; 220 / 2004$, de 29 de noviembre, FJ 6..$^{\circ}$; 63/2005, de 14 de marzo, FJ 12..$^{\circ}$; 153/2005, de 6 de junio, FJ 2. ${ }^{\circ} ; 233 / 2005$, de 26 de septiembre, FJ $12 .^{\circ}$, y 4/2007, de 15 de enero, FJ 4..$^{\circ}$ ).

6 Así lo dice la propia STC 58/2016, de 17 de marzo, FJ 5. ${ }^{\circ}:$ «[E]n el caso del derecho a un proceso sin dilaciones indebidas la denuncia de la vulneración ha de efectuarse mientras el proceso judicial está aún pendiente, con el fin precisamente de poner fin a la dilación denunciada, puesto que de lo que se trata es de conseguir que el órgano judicial dicte la resolución que proceda sin más demora. De este modo, si las supuestas dilaciones no subsisten en el momento de interponerse el recurso de amparo, entonces esta queja pierde su objeto, toda vez que la alegación de la lesión del derecho fundamental a un proceso sin dilaciones indebidas "carece de sentido cuando el procedimiento ya ha finalizado" (entre otras muchas, SSTC 51/1985, de 10 de abril, FJ 4. ${ }^{\circ}$; 146/2000, de 29 de mayo, FJ 3. ${ }^{\circ}$; 237/2001, de 18 de diciembre, FJ 3..$^{\circ} ; 73 / 2004$, de 22 de abril, FJ $2 .^{\circ}$, y 126/2011, de 18 de julio, FJ 5. ${ }^{\circ}$ ); la apreciación en el proceso constitucional de amparo de las pretendidas dilaciones indebidas "no podría conducir a que este Tribunal adoptase medida alguna para hacerlas cesar" 
damentales. La conclusión sobrevenida del proceso ordinario en el que se produjo la vulneración, con posterioridad a la interposición de la demanda de amparo, no determina la pérdida de objeto del recurso, dado que el Tribunal Constitucional puede otorgar el amparo con efectos meramente declarativos $^{7}$, lo que tendrá valor probatorio a efectos de reconocer, por la vía contencioso-administrativa, el funcionamiento anormal de la Administración de Justicia.

La singularidad del derecho fundamental invocado, sumada a la regulación contenida en el art. 102 bis.2 LJCA, es lo que condujo al planteamiento del recurso de amparo frente a resoluciones del secretario judicial, sin otorgar previamente al juez de lo contencioso-administrativo la posibilidad de pronunciarse sobre la denunciada lesión del derecho fundamental. El recurrente en amparo entendió, a beneficio de inventario, que la exigencia legal de agotamiento de la vía judicial previa al recurso de amparo estaba perfectamente cumplida al no establecer la ley un recurso específico contra el decreto del secretario; en este supuesto, por consiguiente, se podía acudir directamente ante el Tribunal Constitucional en impugnación del decreto del secretario.

Planteada la controversia en estos términos, era evidente que el tenor del art. 102 bis LJCA conducía en el caso a un callejón sin salida. La aplicación de la norma en sus términos estrictos — de quererse preservar el control judicial del derecho fundamental cuya denuncia se invocaba, como paso previo a acudir ante el Tribunal Constitucional en amparo- conducía a tener que esperar a la sentencia de primera instancia para pedir al juez la nulidad del señalamiento por vulnerar el derecho fundamental, sin posibilidad de reparar la dilación indebida tempestivamente denunciada, toda vez que la sentencia sería en todo caso posterior al juicio que, como se ha visto, estaba señalado tres años después (es decir, la impugnación no impediría la plena ejecución del señalamiento cuestionado); y, además, la satisfacción del requisito de agotamiento de la vía judicial previa al amparo, en los términos indicados, frustraría las expectativas de éxito de la demanda de amparo: como hemos señalado, la doctrina constitucional entiende que la demanda de amparo por vulneración del derecho al proceso sin dilaciones indebidas está abocada al fracaso cuando el proceso estaba terminado al tiempo de su interposición. Al mismo tiempo, tampo-

(SSTC 224/1991, de 25 de noviembre, FJ 2. ${ }^{\circ}$; 97/2003, de 2 de junio, FJ 4. ${ }^{\circ}$, y 147/2006, de 8 de mayo, FJ único, por todas)».

7 Vid., por ejemplo, las SSTC 89/2014, de 9 de junio, FJ 7. ${ }^{\circ}$, y 75/2016, de 25 de abril, entre otras. 
co estaba claro que el decreto resolutorio del recurso de reposición agotara debidamente la vía judicial, en la medida en que se trataba de una resolución procesal dictada por quien no ejerce jurisdicción y sin posibilidad de revisión por quien ostenta la exclusiva potestad de tutelar los derechos de los ciudadanos (y específicamente, lo derechos fundamentales) ante la jurisdicción ordinaria, esto es, por el juez.

A diferencia de la tesis sostenida por el recurrente, la Sección Cuarta del Tribunal Constitucional (a quien por turno de reparto correspondía decidir sobre la admisión a trámite del recurso de amparo) se planteó dudas acerca del cumplimiento del presupuesto procesal de agotamiento de la vía judicial previa, toda vez que, en efecto, se promovía un recurso por violación de un derecho fundamental que tenía su origen «inmediato y directo en un acto u omisión de un órgano judicial» (art. 44 LOTC) pero en el que no había habido resolución judicial alguna. La cuestión era determinar si una resolución de un secretario judicial agotaba o no la vía judicial previa al recurso de amparo, sin previa revisión por el personal jurisdicente del órgano. La complejidad del asunto llevó a la Sección a acordar la elevación del asunto a la Sala Segunda del Tribunal, para que adoptase la decisión procedente sobre la admisión a trámite del recurso de amparo y, en su caso, sobre si cabía entender adecuadamente agotada o no la vía judicial previa al recurso. Como seguidamente exponemos, la Sala acordó la admisión a trámite (Providencia de 15 de marzo de 2012) pero, con suspensión del plazo para dictar sentencia y previo trámite de audiencia a las partes y al Ministerio Fiscal, decidió por unanimidad promover la cuestión interna de inconstitucionalidad.

\section{El planteamiento de la cuestión interna: argumentos de la Sala Segunda del TC}

La decisión fue tomada por el Auto de la Sala Segunda 163/2013, de 9 de septiembre. La Sala advertía, en efecto, la existencia de un óbice de admisibilidad por falta de agotamiento de la vía judicial, pero se planteó la cuestión de si dicho problema era consecuencia del comportamiento del recurrente a la hora de agotar los recursos legalmente establecidos o, de otro modo, nos encontrábamos ante una irregularidad derivada de la propia Ley. Asimismo, planteaba dudas a la Sala la consideración del secretario judicial como órgano judicial a los efectos del art. 44 LOTC, teniendo en cuenta que el secretario judicial no ejerce potestad jurisdiccional, tarea 
reservada en exclusiva a los Juzgados y Tribunales y que se administra «por los jueces y magistrados integrantes del poder judicial» (art. 117.1 CE). Esta última consideración no es controvertida para la Sala, siquiera tras la reforma de la Oficina Judicial por la Ley Orgánica 19/2003 y su ulterior desarrollo procesal por la Ley 13/2009.

La Sala Segunda del Tribunal Constitucional partía en sus razonamientos de la aceptación de que la legislación procesal atribuye al secretario judicial la competencia en materia de señalamientos; como cuestión de política legislativa, se residencia en el secretario judicial la decisión inicial y la revisión sobre el señalamiento acordado, sin atisbarse posibilidad de control por parte del juez de la decisión que haya de adoptarse. En estas condiciones no parecía de recibo apreciar una conducta negligente del recurrente en amparo, pues cualquier posible remedio regulado por la ley y sobre el cual sustentar la revisión por el juez de lo decidido por el secretario sería una solución forzada, una vez acreditada la voluntad legislativa desapoderar al juez de poder para revisar el decreto que resuelve el recurso de reposición contra diligencias de ordenación. La Sala tenía en cuenta también que la doctrina constitucional contempla el derecho fundamental al recurso (del que es emanación el art. 102 bis LJCA) como un derecho de configuración legal; esto es, que el legislador es soberano para establecer el régimen de recursos contra resoluciones del órgano judicial de acuerdo con criterios de política legislativa, con la sola excepción del derecho a la revisión de la condena penal por un tribunal superior (ex art. 14.5 del Pacto Internacional de Derechos Civiles y Políticos y del art. 2 del Protocolo núm. 7 al CEDH): no existe, por tanto, otro derecho fundamental - a salvo de la señalada excepción- que el derecho a los recursos legalmente establecidos. Lege lata, pues, la garantía de revisión jurisdiccional de lo decidido por el secretario judicial en relación con el señalamiento, como paso previo para acceder al recurso de amparo, se tendría que producir a través de un cauce no previsto (más bien lo contrario) en las normas procesales, lo que probablemente iría más allá de lo que es lógica y procesalmente exigible al recurrente.

Al mismo tiempo, la decisión legislativa de reservar el señalamiento de las vistas al secretario judicial era plenamente consciente, por lo que cualquier solución que se desviase de un designio legal (que, por otra parte y como decimos, forma parte de la soberanía de legislador como es el establecimiento del régimen de recursos contra las resoluciones del proceso), dirigida a garantizar la revisión por el juez de lo recibido por el secretario se tornaba extravagante, atendiendo a las circunstancias del caso. 
Estas reservas de la Sala se comparten plenamente (ello, al margen de la crítica desfavorable que merece la opción legislativa de apartar de la decisión del juez todo lo relativo a la admisión de la demanda y la fijación de los señalamientos, cuestiones que, en nuestra opinión, afectan directamente al ejercicio de la potestad jurisdiccional, en los estrictos términos a que alude la STC 56/1990 como ámbito exclusivo de la función constitucional de jueces y magistrados y que exceden del objeto de este comentario). En efecto, la aplicación de cualesquiera otros instrumentos previstos en la ley para garantizar la revisión jurisdiccional de lo decidido por el secretario en materia de señalamientos parecía forzada. Por ejemplo, el art. 165 LOPJ atribuye al juez la dirección e inspección de todos los asuntos y la adopción de las resoluciones que la buena marcha de la Administración de Justicia aconseje, pero eso no parece suficiente por sí solo para obviar lo previsto por el art. 102 bis LJCA. Ocurre lo mismo con la facultad que el art. 182.5 LEC atribuye al juez o presidente con el fin de «decidir sobre el señalamiento», norma que no habilitaría a éstos para revisar el señalamiento previamente acordado por el secretario a través de un recurso que no menciona la ley: esta decisión se produce dentro de la dinámica interna entre juez y secretario, antes de que la parte haya tomado razón del señalamiento efectuado, y así se acredita por el hecho de que el juez decide sobre la cuestión tras la dación de cuentas realizada por el secretario y antes de la notificación del señalamiento a las partes. Igualmente forzada parecería la posibilidad de promover un incidente de nulidad de actuaciones, a riesgo de desvirtuar los rígidos presupuestos que impone el art. 241 LOPJ para su planteamiento; en último término, la posibilidad prevista por el art. 63 LJCA (que permite la alteración del orden de los señalamientos previamente acordados por circunstancias excepcionales, permitiendo anteponerlos a los demás cuyo señalamiento aún no se hubiera hecho) tampoco parece aplicable al caso, como tampoco lo sería el planteamiento de recursos — como el de revisión directa- cuando no están no previstos en la ley.

Todas estas hipotéticas iniciativas estarían a priori abocadas, casi indefectiblemente, al fracaso, y exigirían del recurrente un esfuerzo procesal excesivo a los solos efectos de garantizar el agotamiento de la vía judicial previa. Ello, por otro lado, sería contrario a lo que el propio Tribunal Constitucional ha entendido como conducta negligente del recurrente, puesto que no se puede cuestionar la diligencia de la parte cuando su comportamiento se ajustó a lo previsto en la ley: como ya había afirmado el Tribunal Constitucional, «el presupuesto procesal del agotamiento 
no puede configurarse como la exigencia de interponer cuantos recursos fueren imaginables, incluso aquellos de dudosa viabilidad. El agotamiento queda cumplido con la utilización de aquellos que razonablemente puedan ser considerados como pertinentes sin necesidad de complejos análisis jurídicos» (STC 11/2011, de 28 de febrero, FJ 3. ${ }^{\circ}$, reiterada por la STC 216/2013, de 19 de diciembre, FJ 2..$^{\circ}{ }^{8}$.

Reflexiones como las que se acaban de resumir llevaron a la Sala Segunda del Tribunal Constitucional a concluir que una eventual falta de agotamiento de la vía judicial determinante de la inadmisibilidad a trámite de la demanda de amparo derivaría no de la conducta del recurrente, sino de la propia norma legal aplicada, que era la que, de manera perfectamente consciente, atribuyó en exclusiva al secretario judicial la potestad de decretar el señalamiento de las vistas sin posibilidad de control o revisión ulterior por el juez. Es la propia norma cuestionada, el art. 102 bis LJCA, párrafo dos, la que impediría controlar en el seno del proceso una posible vulneración del derecho fundamental, como forma de preservar el carácter subsidiario del recurso de amparo, y ello fue lo que movió a la Sala a promover la cuestión interna de inconstitucionalidad, al amparo del art. 55.2 LOTC.

$\mathrm{El}$ auto de planteamiento de la cuestión interna de inconstitucionalidad (ATC 163/2013) es consecuencia de razonamientos cercanos a los que se acaba de exponer, tal y como se refleja en su FD 2. ${ }^{\circ}$ :

«Esta línea de argumentación [se refiere a la de entender debidamente agotada la vía judicial previa en el proceso] determina que en este recurso

${ }^{8}$ En la STC 91/2010 se otorgó el amparo por vulneración del art. 24.1 CE en un caso en el que, revocada en apelación la sentencia que estimó la acción principal del proceso, no tuvo en cuenta (y, por tanto, no resolvió) la acción eventualmente acumulada a la principal. La Audiencia Provincial consideró que ello se debió al comportamiento negligente del propio apelado, que se limitó a oponerse a la apelación sin advertir a la Audiencia de la existencia de la acumulación eventual o subsidiaria. El Tribunal Constitucional, sin embargo, dio la razón al recurrente, al entender que ese comportamiento se había ajustado a lo dispuesto por la LEC para el recurso de apelación civil: había sido, por tanto, coherente que sólo apelase el demandado, pues el demandado había sido la parte perdedora del proceso, sin que pueda considerarse negligente que el apelado (la parte vencedora) no se adhiriera preventivamente a la apelación para el evento de que el recurso de apelación contra la pretensión principal fuera estimado. La doctrina de esta sentencia y de las que en ella se reproducen es aplicable al caso: en efecto, no puede considerarse negligente un comportamiento de la parte no previsto por la ley procesal, máxime cuando dicha conducta se ajustó perfectamente a la legalidad. No es exigible, en consecuencia, la observancia de conductas creativas como las sugeridas en el texto, lo que conduce a no considerar imputable al recurrente una eventual falta de agotamiento por no existir un control judicial de lo decidido por el secretario judicial. 
de amparo se esté recurriendo, bajo la cobertura del art. 44 LOTC, un acto de un órgano judicial que, sin embargo, no emana del titular del mismo, es decir, que no es dictado por el juez o magistrado, sino por la Secretaria Judicial de aquél, lo que ciertamente plantea una situación no solamente atípica, sino problemática en cuanto a su encaje en el amparo contra actos judiciales a que se refiere el citado art. 44 LOTC. Recordemos que dicho precepto permite la interposición del recurso contra las violaciones de los derechos y libertades protegibles en amparo "que tuvieran su origen inmediato y directo en un acto u omisión de un órgano judicial”, expresión esta última que ha de entenderse referida, de conformidad con las previsiones del art. 117 CE, a los Juzgados y Tribunales servidos por jueces y magistrados integrados en el Poder Judicial, y a los que corresponde el ejercicio de la potestad jurisdiccional, juzgando y haciendo ejecutar lo juzgado, sin que quepa realizar una interpretación amplia de ese concepto que permita convertir en objeto del recurso de amparo todo acto procedente de cualquier sujeto que se encuentre incluido en la organización judicial. Esto es, la lesión constitucional recurrible en amparo sólo podría ser atribuible a una actuación de los órganos judiciales, "que son los llamados a prestar la tutela jurisdiccional de los derechos” (STC 76/1999, de 26 de abril)».

A partir de dichos razonamientos, la Sala entiende procedente el planteamiento al Pleno del Tribunal Constitucional de la cuestión interna de inconstitucionalidad respecto del art. 102 bis, apartado 2, LJCA, en la medida en que este precepto excluye del recurso directo de revisión el decreto del secretario judicial resolutivo del recurso de reposición contra las diligencias de ordenación del secretario del Juzgado, y, entre ellas, la que señala el día para la celebración de la vista en el procedimiento abreviado, «privando así al justiciable de la posibilidad de someter a la decisión última del titular del órgano una cuestión tan importante como es la relativa a la afección de un derecho fundamental, que en el presente caso se refiere, como ya ha quedado expuesto, al derecho a un proceso sin dilaciones indebidas ${ }^{9}$, entendiendo que la norma podría haber lesionado el derecho a la tutela judicial efectiva del art. 24.1 CE por excluir del control jurisdiccional la tutela de determinados derechos, decisión que sería aceptada por el Pleno del Tribunal Constitucional en Providencia de 8 de octubre de 2013.

Merece la pena hacer un breve comentario sobre dos cuestiones que se ponen de relieve en estas resoluciones. En primer lugar, el ATC 163/2013

\footnotetext{
9 ATC 163/2013, FD 2. ${ }^{\circ}$, párrafo tercero.
} 
está anticipando en buena medida el sentido de la sentencia que se habría de dictar después, pues su argumentación parte casi axiomáticamente, como hecho no controvertido por la Sala, de que el art. 117.3 CE, cuando atribuye la potestad jurisdiccional exclusivamente a los «jueces y tribunales», está hablando, en puridad, de los «jueces y magistrados» que, según el apartado 1 del art. $117 \mathrm{CE}$, son «integrantes del poder judicial, independientes, inamoviles, responsables y sometidos únicamente al imperio de la ley». La cuestión, sobre la que vuelve la STC 58/2016, es importante, pues desactiva la tesis según la cual la fórmula del art. 117.3 CE admitiría una interpretación comprensiva también de los actuales letrados de la Administración de Justicia en la noción de «Tribunales»; con la consecuencia adicional de rechazarse que cuando el art. 44.1 LOTC se refiere a los actos u omisiones «de un órgano judicial» como objeto del amparo quepa comprender dentro de ellos los actos decisorios del letrado de la Administración de Justicia. En definitiva, según el Auto, las expresiones «Tribunales» (del art. 117.3 CE) y «órgano judicial» (del art. 44.1 LOTC), cuando atribuyen el ejercicio de potestad jurisdiccional o cuando establecen un cauce específico de tutela de amparo, se refieren no a cualquier acto o decisión del órgano emanado de cualquiera de sus integrantes — del juez al miembro del Cuerpo de Auxilio Procesal—, sino tan sólo a aquellos que son el fruto del estricto ejercicio de dicha potestad en los términos del art. 117.1 constitucional.

La segunda cuestión de interés se refiere a un aspecto procesal de la auto-cuestión, pero determinante de su procedencia. En los términos que se han descrito, podría discutirse si la cuestión interna cumple el requisito que establece el art. 55.2 LOTC, que condiciona la procedencia de la cuestión interna de inconstitucionalidad a que el amparo debiera ser estimado porque «la ley aplicada lesione derechos fundamentales». El problema se encontraría, en definitiva, en el juicio de aplicabilidad y relevancia de la norma ${ }^{10}$. En efecto, en el presente caso, la estimación del amparo nunca podría fundarse en la eventual inconstitucionalidad de la norma cuestionada (art. 102 bis.2 LJCA), puesto que la queja que se formula en la demanda de amparo se refiere exclusivamente a la pretendida lesión del derecho al proceso sin dilaciones indebidas (art. 24.2 CE), y no a la vulneración del derecho a la tutela judicial efectiva (art. 24.1 CE). La lesión, como supra se

${ }^{10}$ Sobre el asunto vid. S. García Couso, El juicio de relevancia en la cuestión de inconstitucionalidad, Madrid, Centro de Estudios Políticos y Constitucionales, 1998, y J. P. URías MARTíneZ, La cuestión interna de inconstitucionalidad, Madrid, McGraw-Hill, 1996. 
ha resumido, vendría generada por lo que el recurrente juzgó como excesiva demora en la celebración de la vista desde la admisión de la demanda, de conformidad con lo acordado en el señalamiento por el secretario judicial (tres años), pero es lo cierto que el régimen de recursos legalmente previsto contra las resoluciones del secretario judicial, resultante de la norma cuestionada, era indiferente al recurrente a efectos de las dilaciones indebidas denunciadas. La presunta lesión del derecho al proceso sin dilaciones indebidas que alega el recurrente no parecería depender de que la decisión del secretario judicial fuera o no revisable ante el juez, sino de la previsión de celebrar una vista una vez pasados tres años desde el momento en que se acordó. Por ello, podría haberse defendido perfectamente en el trámite de admisión de la cuestión interna de inconstitucionalidad que no se daba cumplimiento a este concreto presupuesto, pues en las condiciones señaladas parece producirse una ruptura del enlace lógico-racional entre el recurso de amparo y la cuestión interna de inconstitucionalidad, de suerte que lo que en ésta se decida no tendría por qué incidir de forma directa en lo que se haya de resolver en el recurso de amparo, en el que tan sólo se alude al art. 102 bis.2 LJCA a los efectos de justificar el agotamiento de la vía judicial previa y el cumplimiento del requisito del art. 44.1.a) LOTC, pero no como fundamento del amparo que se solicita, tal como se ha acreditado en el caso, si se aprecia lo decidido en la sentencia de amparo. La lectura de la STC 63/2016, de 11 de abril, por la que se resuelve el recurso de amparo en el que se planteó la presente cuestión interna, así lo pone de relieve. La Sala Segunda del Tribunal Constitucional, ante la que pendía el recurso, alude al problema estudiado y a la solución dada por la STC 58/2016, para concluir que, a pesar de la irregularidad derivada de la aplicación al caso del art. 102 bis.2 LJCA, no puede apreciarse la concurrencia del defecto de falta de agotamiento de la vía judicial, precisamente por la fecha en que se produce, que en el presente caso pueda apreciarse el óbice de falta de agotamiento de la vía judicial previa, pues el recurrente no podía en modo alguno obtener una respuesta judicial previa de conformidad con lo previsto por la norma cuestionada ${ }^{11}$; ello condujo, por tanto,

${ }^{11}$ La STC 63/2016, de 11 de abril, FJ 2. ${ }^{\circ}$, razona así: «La reciente declaración de la inconstitucionalidad de dicho precepto no permite, precisamente por la fecha en que se produce, que en el presente caso pueda apreciarse el óbice de falta de agotamiento de la vía judicial previa. Es indudable que, en el momento en el que el actor trató de reaccionar contra la presunta lesión de su derecho fundamental a un proceso sin dilaciones indebidas, no podía en modo alguno obtener una respuesta judicial previa dado el veto al respecto previsto en el párrafo primero de aquel precepto, ahora declarado inconstitucional». 
no a la desestimación del recurso de amparo por concurrencia de causa de inadmisión (lo que parecería lógico, como consecuencia de la estimación de la cuestión interna de inconstitucionalidad), sino al otorgamiento del amparo, en éste y en todos los procesos de amparo pendientes de la resolución de la auto-cuestión de inconstitucionalidad ${ }^{12}$.

Pese al problema que apuntamos, tanto la Sala como el Pleno decidieron tramitar y resolver la cuestión interna, considerando que, si bien el art. 102 bis, apartado 2, LJCA no fue el determinante de las dilaciones denunciadas, era lo cierto que dicha norma sí era aplicable en el caso, a efectos de establecer o no el agotamiento de la vía judicial previa. El juicio de aplicabilidad, por lo tanto, no se reserva tan sólo a las normas de las que depende la decisión del proceso, sino que puede ser igualmente positivo cuando se refiere a normas procesales que condicionan el derecho mismo a la decisión de fondo. Algo que, con independencia de las críticas que pueda merecer en el plano técnico-procesal, reafirma el valor doctrinal del fallo y pone de relieve el interés del Tribunal Constitucional en destacar la posición cimera de los jueces y magistrados, «integrantes del poder judicial», como únicos titulares de la potestad jurisdiccional y últimos garantes de la tutela de los derechos y libertades. Así de marcar con claridad el lugar que corresponde al juez y al letrado de la Administración de Justicia en el proceso.

\section{LAS RAZONES DE LA STC 58/2016}

\section{Tutela judicial efectiva y acceso a la jurisdicción}

Todo quedó resuelto en la STC 58/2016, tres años después de la admisión a trámite de la cuestión interna de inconstitucional. Como ha quedado expuesto, el Tribunal Constitucional en pleno ha declarado que el art. 102 bis.2, apartado primero, LJCA es inconstitucional y nulo, en la redacción que le dio la Ley 13/2009, de 3 de noviembre. En su fundamentación, la Sentencia, tras referirse al papel que la Ley atribuye al letrado de la Administración de Justicia (anterior secretario judicial), a raíz del nuevo diseño de la oficina judicial, que se traduce en la suma de nuevas funciones decisorias a sus tradicionales funciones como fedatario público procesal (FD 2), entra en el análisis de la norma cuestionada, para determi-

${ }_{12}$ SSTC 75/2016, 76/2016 y 77/2016, de 25 de abril, y 89/2016, de 9 de mayo. 
nar si, como se sostiene en el Auto de promoción de la cuestión interna de inconstitucionalidad, la norma impide en el caso que el decreto del secretario sea revisado por el juez de forma directa, privándose con ello al justiciable de la posibilidad de someter a la decisión última del titular del órgano una cuestión que afecta a un derecho fundamental, como es el derecho al proceso sin dilaciones indebidas, cuestión nuclear a la que se dedican los FFDD 3 a 5 de la STC 58/2016.

La controversia se centra, precisamente, en la imposibilidad de recurrir un decreto ante el juez o presidente de la Sala a que se refiere el art. 102 bis, apartado segundo, LJCA. Para el Tribunal Constitucional, lo relevante del caso es la posibilidad de que se plantee un procedimiento de amparo de los previstos por el art. 44 LOTC, directamente contra una resolución procesal del letrado de la Administración de Justicia, punto en el que se centró la argumentación del ATC 163/2013, como anteriormente se ha expuesto. La Sentencia lo expresa en los siguientes términos (FD 3):

«La duda de constitucionalidad afecta pues, en los términos expuestos, al régimen de recursos legalmente establecido contra los decretos de los letrados de la Administración de Justicia en el proceso contenciosoadministrativo resolutivos de la reposición, en la medida en que su aplicación pueda impedir que las decisiones procesales de aquellos en los que resulte afectado un derecho fundamental (como lo es, en el caso en que se plantea la cuestión, el derecho a un proceso sin dilaciones indebidas, en conexión con el derecho a la tutela judicial efectiva) sean revisadas por los Jueces y Tribunales, titulares en exclusiva de la potestad jurisdiccional (art. 117.3 CE). Se vedaría así que los jueces y magistrados, como primeros garantes de los derechos fundamentales en nuestro ordenamiento jurídico, dispensen la tutela judicial efectiva sin indefensión que a todos garantiza el art. 24.1 CE y hagan efectiva la subsidiariedad que caracteriza al proceso constitucional de amparo (por todas, SSTC 147/1994, de 12 de mayo, FJ 2. ${ }^{\circ} ; 71 / 2000$, de 13 de marzo, FJ 3. ${ }^{\circ} ; 214 / 2000$, de 18 de septiembre, FJ $3 .^{\circ}$; 13/2005, de 31 de enero, FJ $3 .^{\circ}$, y 150/2011, de 29 de septiembre, FJ $\left.11 .^{\circ}\right)_{\gg}$.

La respuesta que se da a esta pregunta es favorable a la tesis mantenida en el Auto de promoción. De forma unánime, el Pleno del Tribunal Constitucional entiende que el primer párrafo del art. 102 bis.2 LJCA es incompatible con el derecho a la tutela judicial efectiva (art. 24.1 CE) y con los principios de exclusividad de la potestad jurisdiccional y de 
«reserva de jurisdicción» ${ }^{13}$ consagrado por el art. 117.3 CE, que deriva de la nota de independencia inherente a la potestad jurisdiccional, que garantiza el art. 117.1 CE, y que se concibe con una sumisión del luez a la Ley y al Derecho. El Tribunal, amparándose en decisiones anteriores ${ }^{14}$, recuerda que es a los jueces y magistrados, «individualmente o integrados en Salas o Secciones de Justicia», a quienes corresponde dispensar la tutela judicial, en el ejercicio de la potestad jurisdiccional, que les corresponde exclusivamente. Ello se entiende como una realidad «consustancial a todo Estado democrático» ${ }^{15}$, que nace precisamente de la garantía de independencia prevista por el art. 117.1 CE, «atributo consustancial a la función de juzgar, en cuanto implica que jueces y tribunales no están subordinados en el ejercicio de su función jurisdiccional a ningún otro poder público, sino sometidos única y exclusivamente "al imperio de la ley", esto es, sujetos al Derecho» ${ }^{16}$.

El secretario judicial no ejerce, por tanto, potestad jurisdiccional ni integra el poder judicial ${ }^{17}$. La sentencia se encarga de matizar que ello no debe suponer un reproche general al modelo de proceso establecido por el legislador, quien es soberano para diseñar los procedimientos judiciales así como el régimen de recursos procedente, siempre y cuando ello no rebase los límites que establece la propia Constitución. Dentro de esa libertad de diseño se encuentra lo que en la sentencia se denomina la «libertad de configuración para elegir el nivel de densidad normativa con que pretende regular una determinada materia» ${ }^{18}$. No es, por tanto, objeto de la cuestión de inconstitucionalidad someter a control abstracto de constitu-

13 STC $181 / 2000$, de 29 de junio, FJ $19 .^{\circ}$

${ }^{14}$ SSTC 108/1986, de 26 de julio, FJ 6. ${ }^{\circ}$; 231/2005, de 26 de septiembre, FJ 7. ${ }^{\circ}$, y $37 / 2012$, de 19 de marzo, FJ 5. ${ }^{\circ}$

15 STC 37/2012, FJ 5. ${ }^{\circ}$

${ }^{16}$ Ibídem, FD 5. ${ }^{\circ}$ : «Por eso la legitimación democrática del Poder Judicial deriva directamente de la Constitución, que configura a la justicia como independiente, sometida únicamente al Derecho y no a opciones políticas. Es más, si en un Estado no existe un poder judicial independiente (independencia que se predica de todos y cada uno de los jueces y magistrados integrantes del poder judicial) entonces lo que no hay es Estado de Derecho, pieza esencial, como es sabido, de un Estado auténticamente constitucional».

${ }_{17}$ Algo, por cierto, ya declarado por la Sentencia del Tribunal de Conflictos de Jurisdicción 4/2011, de 28 de septiembre, comentada por I. DíEZ-PiCAZO GimÉNEZ, «Jurisdicción y resoluciones de los secretarios judiciales. Breves reflexiones a propósito de la sentencia del Tribunal de Conflictos de Jurisdicción de 28 de septiembre de 2011», en El Derecho procesal español del siglo XX a golpe de tango. Liber Amicorum en bomenaje de Juan Montero Aroca, Valencia, Tirant lo Blanch, 2012, pp. 309-318.

18 Tomando como referencia las SSTC 181/2000, de 29 de junio, FJ 19. ${ }^{\circ}$, y 190/2005, de 7 de julio, FJ $6 .^{\circ}$ 
cionalidad el modelo libremente escogido por el legislador (materia que sería propia del objeto de un recurso de inconstitucionalidad que no se planteó, por idéntico motivo, por ninguno de los que tenían legitimación para hacerlo), sino determinar si la norma cuestionada, que es expresión de ese nuevo modelo de oficina judicial, excede los límites de la Constitución cuando, por impedir la revisión por el juez de lo que decide el letrado de la Administración de Justicia, está negando la posición de preeminencia que corresponde a aquél como exclusivo titular de un poder del Estado y único dotado de una independencia de la que el letrado de la Administración de Justicia carece.

Centrada así la cuestión, la Sentencia entiende que la norma cuestionada es contraria a la Constitución y al derecho fundamental a la tutela judicial efectiva, en la medida en que impide la revisión por el juez, en el caso al que se refería la queja de amparo, de lo decidido por quien no ostenta jurisdicción. La decisión se refuerza, además, con el argumento de la STJUE de 18 de febrero de 2016 (asunto C-49/14), que ha declarado no conforme con el Derecho comunitario la conclusión del proceso monitorio (cuando no hay oposición del deudor) tan sólo por decreto del secretario, sin permitir la intervención de un juez que pueda apreciar la existencia o no de cláusulas abusivas ( $\$ \$ 34$ a 55 ).

Pero, lo que a nuestro juicio le otorga aún mayor valor, la Sentencia reconoce que lo mismo que ocurre en el caso enjuiciado (que, como hemos visto, se reduce al supuesto concreto de la denuncia de dilaciones indebidas como consecuencia del señalamiento a tres años vista) pueda producirse en otras ocasiones [FD 5.i.l.l)]. En efecto, el sistema que sale de la Ley 13/2009 establece, desde la opción por aprovechar al máximo el capital humano existente en los órganos judiciales, dentro del que se destaca la posición de los letrados de la Administración de Justicia, por su condición de juristas, que todas las resoluciones que no dicte el juez puedan ser revisadas ante un juez: sea a través del recuso directo (el recurso de revisión), o sea a través de un control diferido, que en el proceso contencioso-administrativo se habría de producir en la impugnación de la sentencia o auto que pongan fin a la instancia. Ello no impide que, como decimos, no puedan darse casos en que la vía judicial se cierre por resolución del letrado de la Administración de Justicia, sin opción a la revisión por el personal jurisdicente, o, siendo este posible, haciéndolo ineficaz ${ }^{19}$.

19 Eso es lo que ha llevado a la sentencia a descartar los argumentos en los que la Abogacía del Estado sustentaba la constitucionalidad de la norma. En concreto, que la Ley juris- 
Es esta concreta apreciación lo que facilita que la doctrina que emana de la STC 58/2016 no se reserve en exclusiva al caso de la aplicación del art. 102 bis.2.I LJCA, sino que ésta pueda - y deba - ser extendida a todos los órdenes jurisdiccionales ${ }^{20}$, en aquellos supuestos en que lo decidido por el secretario pueda no ser revisado el juez, aun afectando a derechos fundamentales (por ejemplo, en el caso del proceso civil, puede ocurrir en el procedimiento de jura de cuentas, arts. 34 y 35 LEC, o en numerosas decisiones dentro del proceso de ejecución forzosa, en donde las resoluciones procesales del secretario judicial son recurribles en reposición y, por el juego del art. 454 bis.1 LEC, sin posibilidad de ulterior revisión directa por el juez (desde la adopción de medidas concretas de afección de bienes y derechos hasta decisiones en sede de realización forzosa, singularmente la convocatoria de la subasta, la aprobación del remate o la declaración de la subasta como desierta) ${ }^{21}$.

La argumentación de la sentencia concluye con una afirmación contundente: «El derecho fundamental garantizado por el art. 24.1 CE comporta que la tutela de los derechos e intereses legítimos de los justiciables sea dispensada por los jueces y Tribunales, a quienes está constitucionalmente reservado en exclusividad el ejercicio de la potestad jurisdiccional (art. 117.3 CE)». Este axioma - queremos resaltarlo como merece- «veda que el legislador excluya de manera absoluta e incondicionada la

diccional permitía el control de la resolución en el recurso que procediera contra la Sentencia (así, en el anulado art. 102 bis.2, apartado 1, LJCA). Ello es cierto pero, como supra hemos argumentado, el control diferido en el caso no sólo consumaría la dilación denunciada, sino que además conduciría a la desestimación del amparo, por la propia singularidad de tratamiento procesal de este derecho fundamental por el cauce del amparo constitucional.

${ }^{20}$ Así lo ha defendido recientemente, por ejemplo, en opinión que compartimos, J. Banacloche Palao, «Todas las resoluciones de los letrados de la Administración de Justicia son revisables en todas las jurisdicciones. La inevitable extensión de la STC 58/2016, de 17 de marzo», Diario La Ley, núm. 8779, Sección Tribuna, 9 de junio de 2016, ref. D-233, passim.

${ }^{21}$ El art. 454 bis.1 LEC (también introducido por la Ley 13/2009) contiene, no obstante, una diferencia sustancial con el art. 102 bis.2.I LJCA. Si en este segundo el control diferido del decreto resolutorio del recurso de reposición se debe hacer en el recurso procedente contra la sentencia, en aquel dicho control se debería hacer en «la primera audiencia ante el Tribunal antes de la toma de la decisión» o, si no fuera ello posible por el estado de los autos, «mediante escrito antes de que se dicte la resolución definitiva, para que se solvente en ella». Ello quiere decir que, de haberse planteado el RA 4577-2011 en un proceso civil, la solución de este Tribunal Constitucional no necesariamente hubiera sido idéntica a la dada por la STC 58/2016, en la medida en que el art. 454 bis LEC da oportunidades de someter a control las dilaciones indebidas a tiempo de promover, en su caso, el recurso de amparo ante el Tribunal Constitucional con expectativas de éxito (a salvo, por supuesto, de la concurrencia de especial trascendencia constitucional). 
posibilidad de recurso judicial contra los decretos de los Letrados de la Administración de Justicia resolutorios de la reposición, como acontece en el cuestionado párrafo primero del art. 102 bis.2 LJCA» [FD 7.i).l)]:

«Entenderlo de otro modo supondría admitir la existencia de un sector de inmunidad jurisdiccional, lo que no se compadece con el derecho a la tutela judicial efectiva (así, STC 149/2000, de 1 de junio, FJ 3 , para otro supuesto de exclusión de recurso judicial) y conduce a privar al justiciable de su derecho a que la decisión procesal del letrado de la Administración de Justicia sea examinada y revisada por quien está investido de jurisdicción (esto es, por el juez o Tribunal), lo que constituiría una patente violación del derecho a la tutela judicial efectiva (SSTC 115/1999, de 14 de junio, FJ 4, y 208/2015, de 5 de octubre, FJ 5)».

Poco margen a la interpretación deja la sentencia comentada: la norma que se cuestiona incurre en «insalvable inconstitucionalidad», al crear un «espacio de inmunidad jurisdiccional incompatible con el derecho fundamental a la tutela judicial efectiva» y la reserva de jurisdicción a los jueces y Tribunales integrantes del poder judicial, en cuanto «excluye del recurso judicial a determinados decretos definitivos del letrado de la Administración de Justicia», lo que cercena el derecho del justiciable a someter la decisión última al juez o Tribunal, «a quien compete de modo exclusivo la potestad jurisdiccional».

\section{Valoración crítica de la sentencia}

\section{A. Las dificultades de articulación del juicio de relevancia}

La Sentencia 58/2016 del Pleno del Tribunal Constitucional merece, en nuestra opinión, una valoración positiva, reconociendo las dificultades operativas que se planteaban en la cuestión interna de inconstitucionalidad, que se ponen de relieve en el tiempo transcurrido entre su admisión a trámite, en octubre de 2013, y su definitiva terminación, en marzo de 2016.

Parte de esas dificultades se derivan de la necesidad de delimitar perfectamente el objeto del procedimiento. No se trataba en la auto-cuestión de determinar la conformidad con el derecho a la tutela judicial efectiva, o con las exigencias derivadas de la exclusividad de la potestad jurisdiccional en virtud de lo señalado por el art. $117 \mathrm{CE}$, apartados primero y ter- 
cero, del nuevo modelo de oficina judicial diseñado por la Ley Orgánica 19/2003, del 23 de diciembre, y desarrollado por la Ley 13/2009, de 3 de octubre, especialmente en lo referente a las nuevas competencias orgánicas y procesales atribuidas a los secretarios judiciales, sino específicamente de determinar la conformidad del precepto cuestionado (el art. 102 bis.2, párrafo primero, LJCA) con nuestra Carta magna.

El asunto planteaba la dificultad, ya aludida, de la compleja articulación del juicio relevancia, toda vez que, como se ha visto, el recurso de amparo se basaba en la vulneración del derecho al proceso sin dilaciones indebidas (art. 24.2 CE), cuando la Sala Segunda del Tribunal Constitucional fundamentó el planteamiento de la cuestión interna de inconstitucionalidad en la vulneración del derecho a tutela judicial efectiva (art. 24.1 CE). Mas, como hemos visto, tanto la Sala como el Pleno entendieron que la norma será relevante para la decisión del caso, no tanto a efectos de su resolución sobre fondo, cuanto para establecer el cumplimiento de los presupuestos de admisibilidad del recurso de amparo. Sea esto pacífico o no entre los constitucionalistas, lo cierto es que el Tribunal Constitucional ha puesto de relieve la voluntad de zanjar una cuestión nuclear en el terreno de la Administración de Justicia, cual es la de establecer con la mayor claridad posible cuál es el papel que corresponde a cada uno de los actores a los que nuestra legislación procesal y orgánica atribuye facultades decisorias dentro del proceso.

\section{B. Limites del Tribunal Constitucional, soberanía del legislador $y$ modelo de oficina judicial}

Ello no implica el cuestionamiento del modelo procesal, entendiendo el Alto Tribunal que no es misión del Tribunal Constitucional ejercer tareas propias del legislador. Ésa tal vez sea la cuestión más controvertida en el plano técnico-jurídico, puesto que la Sentencia que comentamos, aun entrando en la cuestión, viene a avalar la constitucionalidad del modelo, algo que ha sido criticado desde sectores académicos, profesionales y judiciales, en la medida en que implica la atribución al secretario judicial (actual letrado de la Administración de Justicia) de funciones que exceden su tradicional papel como fedatario público, encomendándole tareas decisorias en muchas resoluciones de carácter interlocutorio que antes dictaba el juez, con la pretensión de convertir a aquél en algo así como el «juez de lo procesal», reservando a los jueces y magistrados para lo que la STC 56/1990 
entendió como ámbito «estrictamente jurisdiccional», a efecto de deslindar las competencias que correspondían al Consejo General del Poder Judicial, gobierno de la nación y Comunidades Autónomas.

No es cuestión aquí de reiterar críticas ya vertidas y publicadas, excediendo los términos de lo que no es más que un comentario a una trascendente decisión, pero, a modo de simple apunte, cabe poner de relieve que, en la medida en que los secretarios judiciales carecen de las notas de imparcialidad, independencia y desinterés objetivo que caracterizan sustancialmente a los Jueces y Magistrados como titulares de la función jurisdiccional, y que se organizan en virtud de criterios de dependencia, con subordinación jerárquica a la Secretaría General del Ministerio de Justicia y a las instrucciones que de ésta emanen (es decir, del poder ejecutivo), la atribución a aquéllos de funciones decisorias dentro del proceso conduce a lo que se ha dado en denominar la administrativización del proceso ${ }^{22}$.

Puede ser loable la intención del legislador de cambiar el rol de los secretarios judiciales, así como de aprovechar su capital humano para coadyuvar a la labor del juez o descargar a éste de ciertas decisiones en el ámbito de lo no definitivo o en otros como ellos, por ejemplo el de la ejecución forzosa. Sin embargo, esa decisión política no debería poner en cuestión nociones elementales sobre las que se articula nuestro sistema procesal, dado que la consideración de que lo estrictamente jurisdiccional es tan sólo lo que determina el juicio de fondo en un proceso no deja de ser un desideratum del legislador. Todas las decisiones que se toman dentro de un proceso son jurisdiccionales en la medida en que son antecedente lógico de la decisión final que se ha de dictar (esto, por supuesto, siempre que se admita que el juez puede decidir gracias a que dispone de un instrumento que así se lo permite, integrado por una serie de actos que se desarrollan siguiendo una secuencia lógica, que denominamos nemine discrepante proceso en el que se producen numerosas decisiones, no todas ellas de ordenación material).

Esta crítica general del modelo podría extenderse a actuaciones concretas del proceso, que, según la regulación vigente, pertenecen al ámbito de las competencias del letrado de la Administración de Justicia, pero que muy difícilmente pueden deslindarse de lo que entendemos como «estrictamente jurisdiccional»: pensamos, por ejemplo, en las referentes a

22 J. Banacloche Palao, «El proyecto de Nueva Oficina Judicial: ‘hacia un nuevo proceso administrativizado?», Diario La Ley, núm. 7251, Sección Doctrina, 29 de septiembre de 2009, año XXX, ref. D-302. 
la admisión a trámite de la demanda y, por supuesto también, a la que se impugnó en el recurso de amparo que ha traído causa de la presente cuestión interna de inconstitucionalidad, es decir, la decisión del señalamiento, cuestiones que afectan muy directamente al trabajo y organización de los jueces, y que, conforme a su actual regulación, permitirían al letrado de la Administración de Justicia decidir cuándo y cómo tiene que trabajar el juez, sin necesidad de obtener la conformidad o el aval de éste.

En el desarrollo del modelo, compleja y minuciosamente regulado por la Ley 13/2009, el legislador se limitó en algunas ocasiones a duplicar en nuevos preceptos las normas generales aplicables a los jueces y magistrados. Ello es especialmente visible en la norma objeto de cuestión de inconstitucionalidad, pero también, en la esfera del proceso civil, en preceptos como el vigente apartado segundo del art. 206 LEC (que regula las resoluciones de los secretarios judiciales) y en el art. 454 bis LEC (regulador de los recursos contra resoluciones del secretario judicial, en especial, del recurso de revisión directa), que es prácticamente un mero reflejo del régimen de recursos contra resoluciones no definitivas dictadas por los jueces y magistrados. En esta forma de legislar ${ }^{23}$ está el origen de muchos de los problemas de seguridad jurídica que actualmente se plantean ante los órganos judiciales y, por supuesto, el que resuelve la STC 58/2016, por lo cual lo que en ella se revela no es más que la existencia de dos sendas paralelas dentro de cada proceso, que difuminan la función del juez y la consideración del Juzgado como unidad orgánica dentro de la cual se ejerce la jurisdicción, bajo la titularidad de un integrante unipersonal o colegiado del Poder judicial, en favor de una noción de oficina judicial que dificulta con facilidad la identificación por parte del justiciable del órgano que resuelve, y diluye la cadena jerárquica que finalmente debería regir la organización del trabajo, así como la atribución y distribución de responsabilidades entre los funcionarios que la componen.

En definitiva, la nueva consideración de los letrados de la Administración de Justicia no puede implicar, no implica de hecho, la negación o el ocultamiento de la posición cimera que en la Administración de Justicia ocupan quienes son exclusivos titulares de la función jurisdiccional. Por ello, a pesar de la discutible aceptación del nuevo modelo de oficina y a que no se aborde dicha cuestión en la sentencia (como decimos, por ser

${ }^{23}$ A la que nos hemos referido, con extensión, en AAVV, J. Banacloche PalaO (coord.), Los procesos declarativos de la ley de enjuiciamiento civil, Madrid, Civitas Thompson Reuters, 2012, pp. 151 a 162. En esta misma obra, sobre el nuevo régimen de recursos, vid. pp. 377 y ss., redactadas por A. GUTIÉRREZ BERLINCHES. 
ajena al objeto de la cuestión de inconstitucionalidad), lo decidido entraña un gran valor por contribuir a la seguridad jurídica, y a la reafirmación del papel de los jueces y magistrados dentro del proceso. Reiteramos el último razonamiento contenido en su FD 7: entenderlo de otro modo «supondría admitir la existencia de un sector de inmunidad jurisdiccional lo que no se compadece con el derecho tutela judicial efectiva».

\section{Cómo poner remedio a la imposibilidad legal de recurrir las resoluciones del letrado de la Administración de Justicia: Derecho transitorio}

Otra dificultad a la que se enfrentó el Tribunal Constitucional en esta sentencia es la de afrontar las consecuencias que se derivarían de la eventual estimación de la cuestión interna de inconstitucionalidad. Nos referimos, en concreto, a qué se debería hacer en caso de declararse la inconstitucionalidad de la norma, como así ha ocurrido. Puesto que, en puridad, una sentencia que declarase inconstitucional el art. 102 bis.2 LJCA dirige un mandato legislador ordinario, destinado a dar cobertura a una omisión legal de la que se deriva la infracción de un derecho fundamental. La cuestión es, en resumidas cuentas, cómo salvar la omisión legal hasta el momento en el que el legislador decida ejecutar lo establecido en la sentencia, es decir, garantizar que todas las resoluciones dictadas en el proceso puedan ser revisadas por el personal jurisdicente, tratando de aportar claridad en un momento de incertidumbre jurídica.

La STC 58/2016 se plantea esta cuestión en su FD 6, en el que se aclara que nuestro ordenamiento procesal carece de instrumentos que permitan completar la omisión legislativa y, a través de ello, efectuar una interpretación conforme a la Constitución de la norma cuestión. De este modo, se descarta que el incidente de nulidad de actuaciones pueda cumplir esa función, al no estar ordenado a dicho fin. Es ésta, desde luego, una cuestión controvertida. En efecto, si atendemos a la regulación del art. 241 LOPJ y, en su desarrollo, del art. 228 LEC, se evidencian las dificultades a que nos referimos. La procedencia del incidente extraordinario de nulidad de actuaciones se condiciona, en primer lugar, a que la causa de la nulidad o la vulneración del derecho fundamental que se denuncia no haya podido denunciarse antes de recaer resolución que ponga fin al proceso, y siempre «que dicha resolución no sea susceptible de recurso ordinario ni extraordinario» [art. 241.1.i) y f.) LOPJ]. Aplicando esta norma al caso (esto es, a la 
cuestión del señalamiento de la vista del procedimiento abreviado contencioso-administrativo) resulta, por una parte, que la cuestión que se plantea sí había sido denunciada ya (dado que se interpuso un recurso de reposición contra diligencia de ordenación) y, por otra, había sido susceptible de recurso ordinario (precisamente el propio recurso de reposición); en otras palabras, la resolución que había ocasionado las dilaciones indebidas no era el decreto que resolvió el recurso de reposición, sino la diligencia de ordenación que acordó señalamiento a tres años vista, resolución que no sólo podía ser recurrida, sino que de hecho lo fue.

Asimismo, establecen los preceptos mencionados que el competente para conocer del incidente extraordinario de nulidad de actuaciones es «el mismo juzgado o tribunal que dictó la resolución que hubiere adquirido firmeza»: esto segundo genera ciertas dudas de interpretación, dado que lo que pretende la norma, a nuestro entender, es que la nulidad se plantee ante el mismo responsable de la resolución cuya nulidad se pide, de manera que lo procedente, según el plan legal, sería que se promoviese la nulidad actuaciones ante el propio secretario judicial que acordó señalamiento, solución que nada resolvería puesto que nos encontraríamos en la «casilla de salida», si vale la expresión, sin conseguir que lo resuelto por el secretario judicial pueda ser revisado por el juez; conduciendo además a lo que entendemos como un absurdo jurídico, puesto que supondría atribuir a éste funciones decisorias que exceden de la mera ordenación material del proceso.

Cabría otra posible interpretación del art. 241.2.I LOPJ en este concreto extremo que sería interpretar extensivamente la expresión «juzgado o tribunal», en virtud de lo cual se consideraría que el incidente de nulidad de actuaciones debiera ser siempre conocido por el juez o por la Sala, tanto cuando se trata de resoluciones dictadas por él como cuando se trata de resoluciones u otros actos procesales emanados del letrado de la Administración de Justicia, sin que ello conllevase alterar la naturaleza no devolutiva del incidente de nulidad de actuaciones (al modo como ocurre, por ejemplo, cuando se plantea el incidente extraordinario de nulidad por la defectuosa práctica de una notificación o por la publicación de edictos en contra de la doctrina constitucional). Esta solución fue descartada, sin embargo, por el Tribunal Constitucional por considerarse excesivamente alambicada, y por desvirtuar la propia naturaleza del incidente de nulidad, cuando además no todos los posibles casos de impugnación de una resolución procesal del letrado de la Administración de Justicia tienen por qué ser subsumibles en los supuestos que enumera taxativamente 
el art. 238 LOPJ; este argumento sirve también para descartar la viabilidad de la aplicación transitoria del art. 240.2 LOPJ, a estos mismos efectos.

Por las razones expuestas, el Tribunal Constitucional considera [FD 7.i).f]] que, hasta el momento en que el legislador se pronuncie, la forma de garantizar la revisión de los decretos que resuelven el recurso de reposición es el planteamiento del recurso directo de revisión. Esta concreta decisión es prudente, a nuestro juicio, si bien lleva al Tribunal a ejercer labores propias del legislador. En su debe, sin embargo, se encuentra el hecho, de momento imprevisible, de que a su través se puede frustrar la finalidad querida por la reforma del año 2009, cuando se decidió desapoderar a los jueces y magistrados de ciertas funciones decisorias. Si lo que se pretendía era (como tantas veces ha ocurrido en las reformas procesales de los últimos veinte años) descargar de trabajo a los titulares de la potestad jurisdiccional, la eventualidad de que todo lo decidido por el letrado de la Administración de Justicia pueda ser revisado ante aquéllos podría conducir a que, por vía de recurso, los jueces y magistrados acaben conociendo lo que, de acuerdo con él modelo vigente de Oficina Judicial, se pretendió que no conocieran.

\section{CONCLUSIÓN: ELOGIO DEL SECRETARIO JUDICIAL}

Esta reflexión debe concluir necesariamente con un elogio de la función de los secretarios judiciales, colectivo del que han surgido las críticas más agrias contra la STC 58/201624. Siempre desde el respeto a cualesquiera opiniones que pueda merecer una resolución judicial, debemos manifestar nuestra discrepancia con muchas de estas críticas, que justificamos básicamente en la defensa de intereses corporativos, en un cuerpo funcionarial que se encuentra en crisis de identidad.

\footnotetext{
${ }^{24}$ Sin ánimo de exhaustividad vid. L. F. SANTos Del VAlLE, «A propósito del "despropósito" de la STC 58/2016, de 17 de marzo (BOE 22 de abril de 2016)», Revista Aranzadi Doctrinal, núm. 6 (2016); A. MarTínez Guerrero, «Comentario de la STC de 17 de marzo de 2016 a propósito de la revisión de las resoluciones procesales de los letrados de la Administración de Justicia», Diario La Ley, núm. 8790, 24 de junio de 2016, ref. D-253, o M. L. Lozano Gago, J. De Mora Rullán Font y P. Arribas Atienza, «La ordenación material del proceso como función esencial del letrado de la administración de justicia (reivindicación de Herce Quemada: Semblanza de un visionario)», Diario La Ley, núm. 8759, 11 de mayo de 2016, ref. D-198. Con mayor profundidad, L. MARTín CONTRERAS, «Algunas notas sobre la Sentencia del Tribunal Constitucional por la que se declara la inconstitucionalidad del art. 102 bis de la LJCA», Diario La Ley, núm. 8772, Sección Tribuna, 30 de mayo de 2016, ref. D-222.
} 
Por ello creemos pertinente, desde la aceptación de la opinión discrepante, destacar, como decimos, al secretario judicial y su función. Nos referimos, básicamente, a su función pública procesal, capital para el buen curso de las actuaciones procesales y para la validez de éstas, lo que en definitiva determina la suerte de la controversia y la restauración de la paz jurídica el caso concreto. El secretario judicial es un colaborador esencial del juez, cualificado además por su condición de licenciado en derecho y de funcionario público. Pero, a nuestro entender, el secretario judicial no puede ser el juez: cada uno ejerce funciones capitales en el proceso, interdependientes, pero diferentes entre sí en contenido y responsabilidad. El rumbo de la Oficina Judicial y las reformas orgánicas que la han facilitado han proveído un cambio del estatus tradicional del secretario judicial. Hasta el punto de que muchas de esas funciones pueden no ser ejercidas por el propio secretario, sino que pueda delegarlas en otros funcionarios de la Oficina Judicial (pensamos, por ejemplo, en la no necesidad de su presencia en los juicios y vistas, en garantía de la certeza de lo que allí acontece).

Tengo la impresión de que muchas de las reformas que han afectado al secretario judicial y su estatuto jurídico en los últimos años, en las que por cierto existe consenso entre las principales fuerzas políticas parlamentarias, tal y como se puso de relieve ya en el año 2001 en el denominado Pacto de Estado para la reforma de la Justicia, son fruto, por una parte, de la legalización de usos contrarios a la ley (algo, por cierto, que con cierta frecuencia es fuente del legislador procesal: la conversión de la corruptela en ley), circunstancia favorecida por la propia dinámica de funcionamiento de los órganos judiciales, especialmente cuando se trata de dictar ciertas resoluciones judiciales de menor importancia; pero también, por otra, de una aparente crisis de identidad del propio colectivo, evidenciada no sólo en sus nuevas competencias procesales, sino también durante la elaboración de otras normas jurídicas, tales como la Ley de Mediación o la Ley de la Jurisdicción Voluntaria, donde los secretarios judiciales reclamaron con insistencia la asunción de ciertas competencias, en algunos casos obteniendo el éxito; estado de cosas que les ha llevado incluso a plantear cuestiones prejudiciales ${ }^{25}$. El propio cambio de denominación del cuerpo en la reforma de la LOPJ operada por la Ley Orgánica 7/2015, de 21 de julio, patenti-

25 Vid. sobre el particular, F. J. CARRERA HERNÁNDEZ, «¿Son los secretarios judiciales órganos jurisdiccionales a los efectos del planteamiento de cuestiones prejudiciales ante el Tribunal de Justicia?», Revista General de Derecho Europeo, Iustel (38) 2016 (edición electrónica). 
za como motivo del cambio (léase a tal efecto su exposición de motivos), la búsqueda de su distinción con respecto a otros funcionarios de la Oficina Judicial y su consiguiente acercamiento a los jueces y magistrados, a través de su conversión de facto en «jueces de lo procesal».

No es momento éste de analizar en profundidad lo que insisto no es más que la mera impresión basada en datos de experiencia vividos en los últimos veinte años y el conocimiento de muchos integrantes de este colectivo, grandes juristas, así como en las quejas de algunos de ellos por el trato recibido en ocasiones por parte del personal jurisdicente. Sirvan por tanto estas palabras como elogio del colectivo. Rectius, como elogio del secretario judicial, denominación que nos gusta más que la de «letrado de la Administración de Justicia»; el término «letrado» suele reservarse en nuestra estructura administrativa a puestos destinados al asesoramiento o emisión de informes para quien tiene la facultad de tomar la decisión, y, por tanto, sitúa al secretario judicial en un escalón inferior al que, por la trascendencia de sus funciones públicas y decisorias le corresponden por la Ley. 